\title{
ENXERTIA DE PROGÊNIES DE MARACUJAZEIRO-ROXO AUSTRALIANO EM ESPÉCIES NATIVAS ${ }^{1}$
}

\author{
MÁRCIO DE CARVALHO PIRES ${ }^{2}$, OSVALDO KIYOSHI YAMANISHI ${ }^{3}$, JOSÉ RICARDO PEIXOTO $^{4}$ \\ NILTON TADEU VILELA JUNQUEIRA ${ }^{5}$, MARCELO ALVES DE FIGUEIREDO SOUSA ${ }^{6}$
}

RESUMO - O maracujá-roxo (Passiflora edulis), apesar de ser desconhecido no Brasil, pode tornar-se numa fonte de renda alternativa para o agricultor, devido à boa remuneração e aceitação da fruta in natura no mercado europeu. Com o objetivo de avaliar a produção de mudas clonais de maracujá-roxo provenientes da Austrália, foi realizado um experimento no Setor de Fruticultura da Universidade de Brasília entre os meses de maio de 2005 e fevereiro de 2006. O delineamento experimental utilizado foi o de blocos casualizados, com 3 repetições, em arranjo fatorial $7 \times 2 \times 3$, sendo sete porta-enxertos, duas variedades-copa e três épocas de avaliação. A parcela foi formada por 3 plantas úteis. Utilizaram-se como porta-enxertos (PE) as espécies $P$. serrato digitata, $P$. nitida, $P$. coccinea, $P$. quadrangularis, $P$. edulis e $P$. edulis f. flavicarpa híbrido 'EC-2-0' e o híbrido $P$. coccinea X P. setacea, e como copa (CP), as variedades ' $96 \mathrm{~A}^{\prime}$ e '25' de maracujazeiro-roxo. As estacas enraizadas foram transferidas para sacolas plásticas e mantidas sob nebulização intermitente. A enxertia foi efetuada 30 dias após. As avaliações do índice de pegamento foram efetuadas aos 31 e 61 dias após a enxertia (DAE). As combinações CP/PE (entre " 25 " e "96 A" X P. nitida), seguidas das combinações ("25" e "96 A" X P. edulis f. flavicarpa híbrido “EC-2-0"), com 100\%, 90\%, 90\% e 80\%, respectivamente, obtiveram alto índice de pegamento aos 61 DAE. A produção de mudas de maracujazeiro-roxo enxertadas nas espécies de maracujazeiro silvestres e comerciais $P$. nitida, $P$. quadrangularis, $P$. edulis $\mathrm{f}$. flavicarpa híbrido 'EC-2-0' e P. edulis é viável do ponto de vista técnico, pois não ocorreram problemas de incompatibilidade, e os enxertos apresentaram alta taxa de pegamento.

Termos para indexação: P. edulis f. flavicarpa, produção de mudas, espécies silvestres e comerciais, propagação.

\section{GRAFTING OF AUSTRALIAN PURPLE PASSION FRUIT PROGENIES IN DIFFERENT NATIVE SPECIES}

\begin{abstract}
Purple passion fruit (Passiflora edulis), even though is unknown in Brazil, can be an alternative income for the farmers due to good price and acceptance by the European market. Aiming to evaluate the production of clonal nursery plants of Australian purple passion fruit it was realized at the Fruit Section of University of Brasília an experiment from May 2005 to February 2006. Randomized blocks were used with 3 replications in a factorial arrangement $7 \times 2 \times 3$ with 7 rootstock, 2 varieties and 3 periods of evaluation, where each parcel had 3 plants. P. edulis f. flavicarpa, P. serrato digitata, P. nitida, P. coccinea, (P. coccinea $\mathrm{X}$ P. setacea), P. quadrangularis, $P$. edulis e $P$. edulis f. flavicarpa 'EC-2-0' were used as rootstock and as a scion the purple passion fruit ' $96 \mathrm{~A}$ ' and ' 25 ' from Australia. The rooted rootstock was transferred to plastic bags and kept under misting condition and grafted 30 days later. The rooting success rate was evaluated 31 and 61 days after grafting (DAG). The scion/rootstock combination (" 25 " and " $96 \mathrm{~A}$ " X P. nitida) followed by ("25" and "96 A"X P. edulis f. flavicarpa 'EC-2-0') with 100\%, 90\%, 90\% and 80\%, respectively, achieved high success rate $61 \mathrm{DAG}$. The production of purple passion fruits grafted onto native and commercial species as rootstock $P$. nitida, $P$. quadrangularis, $P$. edulis f. flavicarpa 'EC-2-0' and $P$. edulis is viable since there is no evidence of incompatibility and the grafted plants showed high percentage of success rate.

Index terms: P. edulis f. flavicarpa, Purple passion fruit, production of nursery plants, native and commercial species, propagation.
\end{abstract}

\footnotetext{
${ }_{1}^{1}$ (Trabalho 158-08). Recebido em: 13-06-2008. Aceito para publicação em: 30-04-2009. ${ }^{2}$ Engenheiro Agrônomo, Msc. Universidade de Brasília, Brasília - DF, mcpires@unb.br. ${ }^{3}$ Engenheiro Agrônomo, Dr.Universidade de Brasília, Brasília - DF, kiyoshi@unb.br. ${ }^{4}$ Engenheiro Agrônomo, Dr.Universidade de Brasília, Brasília - DF. peixoto@unb.br. ${ }^{5}$ Engenheiro Agrônomo, Dr. Embrapa Cerrados, Brasília - DF, junqueira@cpac.embrapa.br. ${ }^{6}$ Engenheiro Agrônomo, Msc. Universidade de Brasília, Brasília - DF.marcelosousa@unb.br.
} 


\section{INTRODUÇÃO}

O maracujazeiro é originário da América Tropical e possui mais de 150 espécies nativas do Brasil. As mais conhecidas e de maior valor exploração comercial são Passiflora edulis Sims. f. flavicarpa Degener. e P. edulis Sims. (Parizzotto et al., 2004).

Em escala comercial, a propagação do maracujazeiro é realizada por sementes. Devido às características inerentes a esse tipo de propagação e considerando-se a carência de híbridos ou variedades selecionadas, a maioria dos pomares de maracujazeiro é desuniforme, em termos de produção e de qualidade dos frutos obtidos (Almeida et al., 1991).

A cultura do maracujazeiro apresenta problemas, tais como (morte prematura de plantas, fusariose, antracnose, bacteriose, nematoides, murcha do fruto), falta de matrizes para propagação, insuficiência do agente polinizador (mangava), necessidade de polinização manual e obtenção de porta-enxerto (Oliveira et al., 1994).

A enxertia é uma técnica que contribui para o estabelecimento de pomares tecnicamente superiores se comparados àqueles formados por sementes, seja em função do controle de doenças, principalmente à morte prematura de plantas, através de porta-enxertos resistentes ou tolerantes, por multiplicação de material mais produtivo, resistente a pragas e à seca (Ruggiero e Oliveira, 1998; Roncatto et al. 2004), seja mesmo da obtenção de pomares uniformes (Menezes, 1990).

No Brasil, esse método de propagação não é utilizado em escala comercial, ao contrário do que ocorre na África do Sul, onde o principal método de propagação é a enxertia (Grech \& Rijkenberg, 1991). Isso ocorre principalmente pelo maior custo de produção das mudas, maior tempo requerido para sua formação e período de produtividade econômica das plantas que é relativamente curto, variando entre 3 e 4 anos.

As doenças provocadas por patógenos de solo, em maracujazeiro, constituem um dos principais problemas para essa cultura no Brasil. Uma das alternativas de controle é a utilização de porta-enxertos resistentes. Várias espécies de passifloras silvestres vêm apresentando resistência a essas doenças, mas a utilização delas como porta-enxertos, oriundos de sementes, tem sido dificultada pelas diferenças de espessura de caule entre o porta-enxerto e o enxerto da espécie comercial, o que não acontece no caso da utilização de estacas enraizadas como portaenxerto (Meletti et al. 2001, citados por Junqueira et al., 2002).
Maldonado (1991) comparou plantas de maracujazeiro obtidas através de sementes e de enxertia, utilizando $P$. alata, $P$. edulis f. flavicarpa, P. caerulea, Passiflora sp. e P. giberti como porta-enxertos, verificando que as mudas enxertadas levaram, pelo menos, cinco meses da semeadura ao plantio, no local definitivo, enquanto as mudas originárias de sementes demoraram cerca de seis meses.

De acordo com Meletti (2000), é tecnicamente possível multiplicar o maracujazeiro-roxo por enxertia, entretanto comercialmente é um processo que ainda apresenta restrições para uso generalizado. A curto e médio prazos, a adoção da enxertia e o uso de porta-enxertos resistentes à morte prematura de plantas parecem ser a única solução para o cultivo de maracujá em regiões com o histórico da doença.

$\mathrm{Na}$ África do Sul, pomares enxertados têm longevidade de quatro a cinco anos. Relatos de desempenho de plantas enxertadas no Brasil são muito escassos (Meletti 2000), porém Junqueira et al. (2006), trabalhando com clone de maracujáazedo propagado por sementes, estaquia e enxertia em estacas enraizadas de P. nitida do cerrado, verificaram que as plantas propagadas por enxertia tiveram produtividades melhores que as propagadas por semente.

Siqueira \& Pereira (2001) afirmam que a enxertia em escala comercial ainda é inviável economicamente, devido ao maior tempo requerido para a formação da muda, aos maiores custos de produção, às dificuldades e irregularidades na germinação e à pequena disponibilidade de sementes das espécies não comerciais.

Segundo Graça (1994), a enxertia poderá ser uma técnica aconselhável para o maracujazeiro em locais com elevada incidência de doenças e pragas, cujos agentes causais se encontram no solo, inviabilizando o seu cultivo.

Diante do exposto, o presente trabalho teve como objetivo avaliar a resposta das diferentes combinações copa/porta-enxerto, na obtenção de mudas clonais de dois genótipos de maracujazeiro-roxo Australiano ('25' e '96A'), destinados ao plantio comercial.

\section{MATERIAL E MÉTODOS}

Foi realizada a propagação assexuada do maracujazeiro, através da enxertia de Passiflora edulis Sims. (maracujá roxo) sob diferentes espécies de Passiflora silvestres e comerciais: P. serrato digitata, $P$. nitida, $P$. coccinea e o híbrido $P$. coccinea $\mathrm{X} P$. setacea, procedentes da Embrapa Cerrados, Planaltina-DF, $P$. quadrangularis proveniente da 
região de Abadiânia-GO, P. edulis e $P$. edulis f. flavicarpa híbrido 'EC-2-0', provenientes de um pomar cultivado na Estação Experimental de Biologia Setor de Fruticultura da UnB/FAV. O trabalho foi desenvolvido no Setor de Fruticultura da Estação Experimental da Biologia-EEB, Universidade de Brasília, situada no Distrito Federal, a uma latitude sul de $16^{\circ}$, longitude oeste de $48^{\circ}$, e altitude de $1.010 \mathrm{~m}$, entre o período de maio de 2005 e fevereiro de 2006.

O delineamento experimental adotado foi o de blocos casualizados, com 3 repetições, em arranjo fatorial $7 \times 2 \times 3$, sendo sete porta-enxertos, duas variedades-copa e três épocas de avaliação, sendo a parcela formada por 3 plantas úteis.

A casa de vegetação foi protegida por sombrite- $50 \%$, com nebulização intermitente a $18^{\circ} \mathrm{C} \pm 5^{\circ} \mathrm{C}$ à noite e $35^{\circ} \mathrm{C} \pm 5^{\circ} \mathrm{C}$ ao dia, e umidade relativa de $70 \%$ a $100 \%$, sistema de irrigação por aspersão, com a utilização de 'microaspersores' a aproximadamente $1,5 \mathrm{~m}$ de altura da bancada, com vazão de 100 litros/ hora, espaçados 3 metros de uma haste à outra e um turno de rega, três vezes/semana, equipada também com uma miniestação meteorológica.

Foram utilizadas estacas herbáceas retiradas da parte mediana de ramos, sem gemas brotadas, tendo cerca de $20 \mathrm{~cm}$ de comprimento e $0,4 \mathrm{~cm}$ de diâmetro, de plantas adultas de Passiflora serrato digitata, $P$. nitida, $P$. coccinea, o híbrido $P$. coccinea $\mathrm{X}$ P. setacea, $P$. quadrangularis, $P$. edulis e $P$. edulis f. flavicarpa híbrido 'EC-20', utilizando tesouras de poda, sacos plásticos, caixa térmica, canivete e água para manter as estacas hidratadas. As estacas passaram por tratamento, ou seja, foram desinfestadas com solução de Amônia quaternária $50 \%$ Chemitec $®$, logo após sofreram um corte em formato de bisel em suas bases, tiveram as bases imersas em solução de regulador vegetal, ácido indolbutírico (AIB) na concentração de $500 \mathrm{mg} / \mathrm{l}$, por um período variando entre 4 e 5 segundos. Em seguida, foram transplantadas para sacos de polietileno de $22 \times 12 \times 0,01 \mathrm{~mm}$, contendo em $2 / 3$ de seu volume, um substrato à base de subsolo (Latossolo Vermelho de textura média) + esterco de gado curtido, na proporção de $3: 1+100 \mathrm{~g}$ de calcário dolomítico (PRNT 65\%) + 400g de NPK 3-30-16 para 100 litros de solo seco. Sobre este substrato, adicionou-se uma camada de $6 \mathrm{~cm}$ de substrato comercial Bioplant HT®. As estacas tiveram cerca de 3 a $5 \mathrm{~cm}$ de suas bases enterradas na camada de substrato Bioplant HT® sendo mantidas em estufa.

As enxertias foram efetuadas aos 65 dias após a coleta e plantio das estacas, sem proteção do enxerto com saco plástico. O método de enxertia utilizado foi a "garfagem em fenda cheia". Os garfos utilizados no processo de enxertia (brotações de segundo ciclo) tinham cerca de 5 a $10 \mathrm{~cm}$ de comprimento e 0,2 a $0,4 \mathrm{~cm}$ de diâmetro. Foram colhidos no período matutino entre 5 e 6 horas da manhã, sendo envolvidos em sacos plásticos e armazenados em caixa térmica. Após este processo, os garfos foram submetidos a um tratamento com solução de Amônia Quaternária 50\% Chemitec ${ }^{\circledR}$, sendo mergulhados por um período de 2 a 3 minutos. Em cada garfo, foram preservados apenas dois pares de folhas primárias. Os garfos foram retirados de plantas de maracujazeiro-roxo cv. " $96 \mathrm{~A}$ " e " 25 ", introduzidos da Austrália, cultivadas em um pomar localizado na estação experimental da biologia no setor de fruticultura da UnB, Brasília-DF. As plantas utilizadas como porta-enxerto, eram estacas enraizadas e brotadas, sendo que durante sua formação sofreram desbrotamento para a formação de uma única haste. Antes da enxertia, as mudas foram submetidas a um período de aclimatação de 35 dias ao ar livre, sendo irrigadas uma vez ao dia. Também foram usadas pulverizações com fungicida Metalaxil/Mancozeb (Ridomil Mancozeb® BR) a 0,024 \% e 0,192\% de i.a., respectivamente. As mudas dos porta-enxertos foram submetidas a adubações foliares quinzenais, utilizando produto comercial Plantim II ${ }^{\circledR} \mathrm{e}$, antes de serem enxertadas, foram submetidas ao período de seca (estresse hídrico) por 2 dias, prática recomendada por viveiristas da Austrália e que garante maior aderência do tecido cambial na união do enxerto ao porta-enxerto.

No processo de produção de mudas de maracujazeiro-roxo, foi avaliado o diâmetro do porta-enxerto, diâmetro do enxerto, altura do enxerto e quantidade de clorofila presente nas folhas com o auxílio de um aparelho eletrônico denominado clorofilômetro SPAD-502 da Minolta (SPAD - Soil and Plant Analysis Development).

As avaliações foram feitas aos trinta e um dias e sessenta e um dias após a enxertia. $\mathrm{Na}$ análise de variância dos dados, para avaliação da significância do efeito dos tratamentos, foi utilizado o teste de F. Compararam-se as medidas entre si, pelo teste de Tukey, ao nível de 5\% de probabilidade (Banzatto; Kronka, 1992).

Os cálculos referentes às análises estatísticas foram executados, utilizando o software SANEST (Zonta \& Machado 1995).

\section{RESULTADOS E DISCUSSÃO}

O diâmetro de porta-enxerto (DPE) mostrou ser uniforme aos 31 dias após a enxertia, sendo que apenas a espécie $P$. coccinea e o híbrido interespecífico entre as espécies $P$. coccinea $\mathrm{X} P$. setacea se 
diferenciaram dos demais nesta mesma época de avaliação (Tabela 1). Aos 61 após a enxertia, todas as espécies apresentaram crescimento significativo do diâmetro de porta-enxerto (DPE), diferindo disso apenas $P$. serrato digitata e $P$. coccinea X $P$. setacea que não apresentaram crescimento significativo em relação aos 31 dias após serem enxertados. Neste mesmo sentido, foi relatado por Pires et al. (2005), que estudando a produção de mudas de três genótipos de maracujazeiro-roxo pelo método de enxertia, constataram incremento no diâmetro do ramo enxertado logo acima do ponto de enxertia e do porta-enxerto (PE) logo abaixo do ponto de enxertia de $9,8 \%$ a $17 \%$ e $5,8 \%$ a $10,8 \%$, respectivamente, no período de 30 a 60 dias após a enxertia (DAE). O diâmetro médio do ramo enxertado logo acima do ponto de enxertia foi equivalente a $60,8 \%$ e $63,9 \%$ do diâmetro do $\mathrm{PE}$ logo abaixo do ponto de enxertia aos 30 e 60 DAE, respectivamente.

O diâmetro do enxerto (DE) onde os genótipos G-25 e 96-A da espécie $P$. edulis foram enxertados, diferenciou-se um do outro quando enxertados em plantas de $P$. quadrangularis e $P$. serrato digitata (Tabela 2). Isso provavelmente ocorreu pelo fato de $P$. quadrangularis ser diferente no que se refere ao formato da estaca (porta-enxerto) em relação ao enxerto. No caso de $P$. serrato digitata, este fato pode ser atribuído à diferenciação de tecidos entre as espécies, sendo que o porta-enxerto apresentou ser um material mais lignificado em relação aos demais materiais usados como porta-enxerto; entretanto, este fato não influenciou significativamente no resultado da enxertia.

Os resultados demonstram que, para todas as espécies, a altura do enxerto (AE) foi superior quando avaliada aos 61 dias após a enxertia. As estacas enxertadas (porta-enxertos) das espécies $P$. edulis e $P$. edulis f. flavicarpa híbrido 'EC-2-0' foram as que proporcionaram maior crescimento de parte aérea (copa), com comprimento de $33,16 \mathrm{~cm}$ e $31,70 \mathrm{~cm}$, respectivamente (Tabelas 3 ). Esse fato pode ser explicado pela maior compatibilidade de tecidos e diâmetro de estacas entre as combinações enxerto e porta-enxerto ( $P$. edulis X $P$. edulis e $P$. edulis X P. edulis f. flavicarpa híbrido 'EC-2-0'); no entanto, este fator não interferiu significativamente no sucesso da enxertia.

Roncatto et al. (2005), avaliando diferentes métodos de enxertia de maracujazeiros nas condições da depressão cuiabana, verificaram que plantas enxertadas pelo método de fenda cheia, aos 30 dias após a enxertia, apresentaram um crescimento médio de $4 \mathrm{~cm}$ a cada 5 dias. As plantas utilizadas pelos autores foram obtidas de sementes oriundas do IAC
(Instituto Agronômico de Campinas-SP) cultivares: IAC 275 e Roxinho miúdo. As possíveis diferenças entre os estudos podem ser explicadas pelas condições edafoclimáticas encontradas entre uma região e outra, ou até mesmo porque as estacas avaliadas por Roncatto, possuíam número maior de folhas, possibilitando assim maior atividade fotossintética e, consequentemente, maior crescimento do enxerto.

Com relação ao SPAD - Soil and Plant Analysis Development, foi observado que todas as espécies avaliadas apresentam maior quantidade de clorofila presente nas folhas aos 61 dias após terem sido enxertadas, o que não quer dizer que esta quantidade de clorofila não tenha aumentado gradativamente com o passar dos dias; no entanto, apenas $P$. coccinea, $P$. serrato digitata e $P$. edulis f. flavicarpa híbrido 'EC2-0' diferiram dos demais quando comparadas às médias de SPAD aos 31 dias após serem enxertados Também pode-se notar que as plantas de $P$. edulis $\mathrm{f}$. flavicarpa híbrido 'EC-2-0' foram as que obtiveram as maiores quantidades de clorofila aos 61 dias após a enxertia (Tabela 4), o que pode ser explicado pela melhor recuperação dos tecidos lesionados no ato da enxertia (diferenciação e cicatrização de tecidos).

Estudando o Índice Relativo de Clorofila (IRC) como um indicativo auxiliar no manejo do nitrogênio em videira, Bôas et al. (2001) encontraram resultados variando de 23,9 a 38,5 unidades (SPAD), de acordo com a posição da folha e a cultivar de videira. Sharaan et al. (1999) observaram valores entre 28,5 a 34,5 em videiras nos campos comerciais do Egito.

Foi observado um índice de pegamento de enxertos variando de $100 \%$ a $30 \%$. As combinações enxertos e porta-enxertos entre $P$. edulis genótipos "25" e "96 A" X P. nitida, seguidas das combinações $P$. edulis genótipos " 25 " e "96 A" X P. edulis $\mathrm{f}$ flavicarpa híbrido 'EC-2-0' foram as melhores, com $100 \%, 90 \%, 90 \%$ e $80 \%$ nesta mesma ordem, sendo representados pelas médias $95 \%$ e $85 \%$, respectivamente. As combinações enxertos porta-enxertos entre $P$. edulis genótipos " 25 " e "96 A" e o híbrido $P$. coccinea $\mathrm{X} P$. setacea foram as que manifestaram os menores índices de pegamento, com 30\% (Tabela 5).

Comparando o desempenho dos porta-enxertos de $P$. edulis, $P$. giberti, $P$. cincinnata, $P$. alata, $P$. caerulea e $P$. foetida, Lima et al. (1999) concluíram que as maiores percentagens de pegamento da enxertia de maracujazeiro-amarelo foram obtidas em $P$. cincinata $(73 \%)$ e $P$. caerulea $(74 \%)$. Com a $P$. foetida e $P$. giberti foi obtida a menor percentagem de pegamento da enxertia (27\%). As taxas de pegamento de enxertos obtidas por Menezes et al. (1994), sobre porta-enxertos oriundos de sementes de diferentes 
espécies de passifloras, foram de apenas $18,7 \%$ de enxertos pegos sobre $P$. nítida e $100 \%$ sobre $P$. caerulea, aos 90 dias após a enxertia.
Já Chaves et al. (2004), estudando a enxertia na cultura do maracujazeiro-azedo, verificaram um índice de pegamento de enxertia de 78,88\% para a espécie sobre $P$. nitida e $55,5 \%$ sobre $P$. setacea.

TABELA 1 - Porcentagem de enxertos pegos de 2 genótipos de Passiflora edulis enxertados em porta-enxerto oriundos de espécies silvestres e Comerciais de Passiflora spp. EEB-Setor de Fruticultura, UnB/FAV Brasília-DF.

\begin{tabular}{|c|c|c|c|}
\hline \multicolumn{2}{|c|}{31 dias após a enxertia } & \multicolumn{2}{|c|}{61 dias após a enxertia } \\
\hline Porta-enxerto & $\%$ Pegamento & Porta-enxerto & $\%$ Pegamento \\
\hline P. edulis f. flavicarpa & 90 & P. edulis f. flavicarpa & 90 \\
\hline P. edulis f. flavicarpa & 100 & P. edulis f. flavicarpa & 80 \\
\hline P. edulis f. flavicarpa & 95 & P. edulis f. flavicarpa & 85 \\
\hline P. edulis & 80 & P. edulis & 80 \\
\hline P. edulis & 80 & P. edulis & 70 \\
\hline P. edulis & 80 & P. edulis & 75 \\
\hline P. nitida & 100 & P. nitida & 100 \\
\hline P. nitida & 90 & P. nitida & 90 \\
\hline P. nitida & 95 & P. nitida & 95 \\
\hline P. coccinea & 70 & P. coccinea & 40 \\
\hline P. coccinea & 90 & P. coccinea & 50 \\
\hline P. coccinea & 80 & P. coccinea & 45 \\
\hline P. coccinea $\mathrm{x}$ setacea & 60 & P. coccinea $\mathrm{x}$ setacea & 30 \\
\hline P. coccinea $\mathrm{x}$ setacea & 100 & P. coccinea $\mathrm{x}$ setacea & 30 \\
\hline P. coccinea $\mathrm{x}$ setacea & 80 & P. coccinea $\times$ setacea & 30 \\
\hline P. serrato digitata & 90 & P. serrato digitata & 40 \\
\hline P. serrato digitata & 90 & P. serrato digitata & 60 \\
\hline P. serrato digitata & 90 & P. serrato digitata & 50 \\
\hline P. quadrangularis & 80 & P. quadrangularis & 70 \\
\hline P. quadrangularis & 90 & P. quadrangularis & 90 \\
\hline P. quadrangularis & 85 & P. quadrangularis & 80 \\
\hline
\end{tabular}

TABELA 2 - Valores referentes ao (DPE) diâmetro do porta-enxerto de cada planta de Passiflora spp. em relação à época de avaliação: 1, 31 e 61 dias após a enxertia, EEB-Setor de Fruticultura, UnB/ FAV Brasília-DF.

\begin{tabular}{cccc}
\hline Espécies & 1 dia & $\begin{array}{r}\text { Época } \\
\text { 31 dias }\end{array}$ & 61 dias \\
\hline P. coccinea & $3,65 \mathrm{cC}$ & $4,31 \mathrm{bB}$ & $5,06 \mathrm{aC}$ \\
P. quadrangularis & $3,55 \mathrm{cC}$ & $5,63 \mathrm{bA}$ & $7,06 \mathrm{aA}$ \\
P. serrato digitata & $4,94 \mathrm{bA}$ & $5,72 \mathrm{aA}$ & $5,90 \mathrm{aB}$ \\
P. edulis & $4,44 \mathrm{cAB}$ & $5,40 \mathrm{bA}$ & $6,50 \mathrm{aAB}$ \\
P. edulis f. flavicarpa 'EC-2-0' & $3,73 \mathrm{cBC}$ & $5,43 \mathrm{bA}$ & $6,03 \mathrm{Ab}$ \\
P. nitida & $4,51 \mathrm{cA}$ & $5,18 \mathrm{bA}$ & $5,89 \mathrm{aB}$ \\
P. coccinea X P. setacea & $3,29 \mathrm{bC}$ & $4,30 \mathrm{aB}$ & $4,62 \mathrm{aC}$ \\
\hline
\end{tabular}

Médias seguidas de mesma letra maiúscula, nas colunas, e letra minúscula, nas linhas, não diferenciam entre si, pelo teste de Tukey, a $5 \%$ de probabilidade. 
TABELA 3 - Valores referentes ao diâmetro do enxerto (DE) de cada planta de Passiflora spp., em relação aos genótipos de P. edulis enxertados, EEB-Setor de Fruticultura, UnB/FAV Brasília-DF.

\begin{tabular}{ccc}
\hline Espécies & G-25 & Enxerto \\
& 96-A \\
\hline P. coccinea & $4,33 \mathrm{cA}$ & $4,35 \mathrm{cA}$ \\
P. quadrangularis & $5,04 \mathrm{bA}$ & $5,79 \mathrm{aA}$ \\
P. serrato digitata & $5,69 \mathrm{aA}$ & $5,34 \mathrm{abA}$ \\
P. edulis & $5,50 \mathrm{abA}$ & $5,38 \mathrm{abA}$ \\
P. edulis f. flavicarpa 'EC-2-0' & $5,03 \mathrm{bA}$ & $5,09 \mathrm{bA}$ \\
P. nitida & $5,20 \mathrm{abA}$ & $5,18 \mathrm{abA}$ \\
P. coccinea X P. setacea & $5,15 \mathrm{cA}$ & $3,98 \mathrm{cA}$ \\
\hline
\end{tabular}

Médias seguidas de mesma letra maiúscula, nas colunas, e letra minúscula, nas linhas, não diferenciam entre si, pelo teste de Tukey, a $5 \%$ de probabilidade.

TABELA 4 - Valores referentes à altura do enxerto (AE) de cada planta de Passiflora spp. em relação a época de avaliação: 1, 31 e 61 dias após a enxertia, EEB-Setor de Fruticultura, UnB/FAV Brasília-DF.

\begin{tabular}{cccc}
\hline Espécies & $\mathbf{1}$ dia & E1 dias & 61 dias \\
\hline P. coccinea & $9,04 \mathrm{bA}$ & $13,04 \mathrm{bA}$ & $20,71 \mathrm{aBC}$ \\
P. quadrangularis & $8,00 \mathrm{bA}$ & $12,64 \mathrm{abA}$ & $16,37 \mathrm{aC}$ \\
P. serrato digitata & $8,83 \mathrm{cA}$ & $18,29 \mathrm{bA}$ & $26,09 \mathrm{aAB}$ \\
P. edulis & $8,87 \mathrm{cA}$ & $16,79 \mathrm{bA}$ & $33,16 \mathrm{aA}$ \\
P. edulis f. flavicarpa 'EC-2-0' & $9,87 \mathrm{cA}$ & $17,63 \mathrm{bA}$ & $31,70 \mathrm{aA}$ \\
P. nitida & $8,87 \mathrm{cA}$ & $15,79 \mathrm{bA}$ & $26,16 \mathrm{aAB}$ \\
P. coccinea X P. setacea & $8,62 \mathrm{bA}$ & $13,81 \mathrm{abA}$ & $17,54 \mathrm{aC}$ \\
\hline
\end{tabular}

Médias seguidas de mesma letra maiúscula, nas colunas, e letra minúscula, nas linhas, não diferenciam entre si, pelo teste de Tukey, a $5 \%$ de probabilidade.

TABELA 5 - Índice Relativo de Clorofila obtido através do clorofilômetro (SPAD-502 da Minolta), de cada planta de Passiflora spp. em relação à época de avaliação: 1, 31 e 61 dias após a enxertia, EEB-Setor de Fruticultura, UnB/FAV Brasília-DF.

\begin{tabular}{|c|c|c|c|}
\hline \multirow{2}{*}{ Espécies } & \multicolumn{3}{|c|}{ Época } \\
\hline & 1 dia & 31 dias & 61 dias \\
\hline P. coccinea & $36,00 \mathrm{aA}$ & $28,75 \mathrm{bB}$ & $37,10 \mathrm{aB}$ \\
\hline P. quadrangularis & $28,92 \mathrm{bB}$ & $38,70 \mathrm{aA}$ & $40,59 \mathrm{aAB}$ \\
\hline P. serrato digitata & $32,20 \mathrm{bAB}$ & $31,65 \mathrm{bAB}$ & $38,23 \mathrm{aAB}$ \\
\hline P. edulis & $38,81 \mathrm{aAB}$ & $27,91 \mathrm{aB}$ & $35,26 \mathrm{aB}$ \\
\hline P. edulis f. flavicarpa 'EC-2-0' & $32,27 \mathrm{bAB}$ & $30,93 \mathrm{bB}$ & $44,50 \mathrm{aA}$ \\
\hline P. nitida & $35,33 \mathrm{aAB}$ & $31,13 \mathrm{aB}$ & $36,69 \mathrm{aB}$ \\
\hline P. coccinea X P. setacea & $30,50 \mathrm{aAB}$ & $32,96 \mathrm{aAB}$ & $34,25 \mathrm{aB}$ \\
\hline
\end{tabular}

Médias seguidas de mesma letra maiúscula, nas colunas, e letra minúscula, nas linhas, não diferenciam entre si, pelo teste de Tukey, a $5 \%$ de probabilidade. 


\section{CONCLUSÕES}

1-A produção de mudas de maracujazeiroroxo Australiano, genótipos "96A" e 'Supersweet 4' ou " 25 " via enxertia em estacas herbáceas enraizadas das espécies $P$. edulis $f$. flavicarpa híbrido 'EC-2-0', P. edulis, P. nitida, P. coccinea, P. quadrangularis, $P$. serrato digitata e o híbrido $P$. coccinea X $P$. setacea é tecnicamente viável.

2-As combinações $P$. edulis genótipos " $96 \mathrm{~A}$ " e 'Supersweet 4' ou '25" espécies (copa), X $P$. nitida, $P$. edulis f. flavicarpa híbrido 'EC-2-0' e $P$. quadrangularis, espécies porta-enxertos, constituem boa alternativa para produção de mudas enxertadas de maracujazeiro-roxo Australiano.

\section{REFERÊNCIAS}

ALEXANDRE, R.S.; WAGNER JUNIOR, A.; NEGREIROS, J.R. da S.; PARIZZOTTO, A.; BRUCKNER, C.H. Germinação de sementes de genótipos de maracujazeiro. Pesquisa Agropecuária Brasileira, Brasília, v.39, n. 12, p.1239-1245, 2004.

ALMEIDA, L. P.; BOARETTO, M. A. C.; de; SANTANA, R. G. Estaquia e comportamento de maracujazeiros (P. edulis Sims. f. Deg.) propagados por via sexual e vegetativa. Revista Brasileira de Fruticultura, Jaboticabal, v.13, n.1, p. 153-156, 1991.

BANZATTO, D. A.; KRONKA, S. do N. Experimentação agrícola. 2. ed. Jaboticabal: Funep, 1992. $247 \mathrm{p}$.

BÔAS, R. L. V.; GODOY, de L. J. G.; PANTANO, S. C. Índice relativo de clorofila: um indicativo auxiliar no manejo do nitrogênio em videira. 2001. 94 f. Dissertação (Doutorado em Produção Vegetal/ Horticultura) - Faculdade de Ciências Agronômicas - Universidade Estadual Paulista, Botucatu, 2001.

CHAVES, R. C.; JUNQUEIRA, N. T. V.; MANICA, I.; PEIXOTO, J. R.; PEREIRA, A. V.; FIALHO, J. F. Enxertia de maracujazeiro-azedo em estacas herbáceas enraizadas de espécies de passiflora nativas. Revista Brasileira de Fruticultura, Jaboticabal, v.26, n 1, p. 120-123, 2004.

GRAÇA, J. Utilização de porta-enxertos do gênero Passiflora para maracujazeiro-amarelo. In: $\mathrm{CON}-$
GRESSO BRASILEIRO DE FRUTICULTURA, 13., 1994. Salvador. Resumos... Salvador: SBF, 1994. v. 3, p. 819-820.

GRECH, N. M.; RIJKENBERG, F. H. J. Laboratory and field evaluation of the performance of Passiflora caerulea as a rootstoch tolerant to certain fungal root pathogens. Journal of Horticultural Science, Ashford, v.66, n.6, p.725-729, 1991.

JUNQUEIRA, N. T. V.; CHAVES, R. C.; MANICA, I.; PEIXOTO, J. R.; PEREIRA, A. V.; FIALHO, J. F Propagação do maracujazeiro-azedo por enxertia em estacas herbáceas enraizadas de espécies de passiflora. Planaltina-DF: Embrapa Cerrados, 2002. 15 p. (Boletim de pesquisa e desenvolvimento)

LIMA, A. de A.; CALDAS, R. C.; CUNHA, M. A. P.; SANTOS FILHO, H. P. Avaliação de porta-enxertos e tipos de enxertia para maracujá-amarelo. Revista Brasileira de Fruticultura, Jaboticabal, v.21, n.3, p.318-321, 1999.

MALDONADO, J. F. M. Utilização de pota-enxertos do gênero Passiflora para maracujazeiro-amarelo $(P$. edulis Sims. f. flavicarpa Deg.). Revista Brasileira de Fruticultura, Jaboticabal, v.13, n.2, p.51-54, 1991.

MELETTI, L. M. M. (Coord.). Propagação de frutíferas tropicais. Guaíba: Agropecuária, 2000. 239p

MENEZES, J. M. T. Seleção de porta-enxertos tolerantes à morte prematura de plantas para $P$. edulis Sims. f. Deg. e comportamento de $P$. nitida H.B.K. na região de Jaboticabal. 1990. 73 f. Dissertação (Mestrado em Melhoramento Genético e Vegetal) -Faculdade de Ciências Agrárias e Veterinárias, Universidade Estadual Paulista, Jaboticabal, 1990.

MENEZES, J. M. T.; OLIVEIRA, J. C.; RUGGIERO, C.; BANZAZTO, D. A. Avaliação da taxa de pegamento de enxertos de maracujá-amarelo sobre espécies tolerantes à "morte prematura de plantas". Científica, Jaboticabal, v.22, n.1, p. 95-140, 1994.

OLIVEIRA, J. C.; NAKAMURA, K.; MAURO, A. O.; CENTURION, M. A. P. C. Aspectos gerais do melhoramento do maracujazeiro. In: SÃO JOSÉ, A.R. Maracujá, produção e mercado. Vitória da Conquista: UESB, 1994. p.27-37.

PIRES, M. C.; YAMANISHY, O. K.; JUNQUEIRA, N. T. V.; PEIXOTO, J. R.; FAGUNDES, G. R. Pro- 
dução de mudas de três genótipos de maracujazeiroroxo pelo método de enxertia. In: REUNIÃO TÉCNICA SOBRE PESQUISA EM MARACUJAZEIRO, 4., 2005..Planaltina. Anais... Planaltina: Embrapa Cerrados, 2005. p. 72-75.

RONCATTO, G.; FERREIRA, L. G.; LENZA, J. B.; DAMASCENO, M. A. P. Avaliação preliminar de diferentes métodos de enxertia de maracujazeiros nas condições da depressão Cuiabana. In: REUNIÃO TÉCNICA SOBRE PESQUISA EM MARACUJAZEIRO, 4., 2005..Planaltina. Anais... Planaltina: Embrapa Cerrados, 2005. p. 64-67.

RONCATTO, G.; OLIVEIRA, J. C.; RUGGIERO, C.; FILHO, G. C, N.; CENTURION, M. A. P. C.; FERREIRA, F. R. Comportamento de maracujazeiro (Passiflora spp.) quanto à morte prematura. Revista Brasileira de Fruticultura, Jaboticabal, v.26, n.3, 552-554, 2004.

RUGGIERO, C., OLIVEIRA, J. C. de. Enxertia do maracujazeiro. In: SIMPÓSIO BRASILEIRO SOBRE A CULTURA DO MARACUJAZEIRO, 1998, Jaboticabal, Resumos... p. 70-92.
SHARAAN, M. M.; EL-SAYED, A. A.; ABOU EL-NOUR, E. A. Predicting nitrogen, magnesium and iron nutritional status perennial crops using a portable chlorophyll meter. Scientia Horticulturae, Amsterdam, v. 82, p. 339-348, 1999.

SIQUEIRA, D. L. de; PEREIRA, W. E. Propagação. In: BRUCKNER, C.H.; PICANÇO, M.C. (Ed.). Maracujá: tecnologia de produção de pós-colheita, agroindústria, mercado. Porto Alegre: Cinco Continentes, 2001. p.85-137.

ZONTA, E.P.; MACHADO,A.A.SANEST-Sistema de análise estatística para microcomputadores. Pelotas: UFPEL, 1995. 48p. (SEI n. 066060, Categoria A) 